\title{
علاقة بين استيعاب المفردات لدى التلاميذ وقدراتهم على ترجمة نص القراءة من تعليم اللغة العربية في المدرسة الثانوية الحكومية باتوسنكر
}

\author{
الكاتبة : رزانة \\ قسم تعليم اللغة العربية في كلية التربية بجامعة السنة الإسلامية

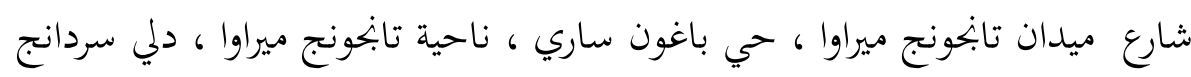

تجريد: استيعاب المفردات هي إحدى عوامل اللغة العربية، وهي التي تحتاج إليها في الترجمة، لأها عاملة من عوامل الترجمة الجيدة. هذه الرسالة تستهدف لمعرفة العلاقة بين استيعاب المفردات لدى التلاميذ وقدراهم على ترجمة نص القراءة من تعليم اللغة العربية في المدرسة الثانوية الحكومية باتوسنكر، هي باستعمال منهجية البحث العلاقي. وتأخذ الكاتبة العينة بطريقة Kluster Sampling، وهي تلاميذ الفصل السابع بعددهم 28 تلميذا. أما نتيجة البحث فهي العلاقة الإيجابية والقوية بين استيعاب المفردات لدى التلاميذ وقدراتم على ترجمة نص القراءة من تعليم اللغة العربية. إذن، لديهم استيعاب المفردات المرتفعة فلديهم قدرة على ترجمة نص القراءة من تعليم اللغة العربية مرتفعة أيضا. وبالعكس، لديهم استيعاب المفردات المنخفضة فلديهم قدرة على ترجمة نص القراءة من تعليم اللغة العربية منخفضة أيضا.

مقدمة

قال عبد الحليم حنفي في كتابه "طرق تعليم اللغة العربية" أن التعليم هو فن من فنون إيصال المادة الدراسية من المعلم إلى أذهان التلاميذ وتغيير أعمالهم، من السيئات إلى الحسنات، ومن الجهل إلى العلم، ومن الظلمات إلى النور بأنشطة تعليمية معينة وبطريقة 
مناسبة وبأقل الجها والنفقات حتى يكصل على أغراض التعليم الكافية والكاملة .ومن أهم مواد التي يتعلمها الناس هي مادة اللغة العربية، كما قال جودات الركابي: لقد زاد النال الاهتمام بتعليم اللغة العربية في خختلف مراحل التدريس لأن هذه اللغة شريفة وهي لسان الإسلام، تؤكد وجودنا وتبني حضارتنا ومن خلالها نطل على أنواع المعرفة. اللغة العربية هي "الكلمات التي يعبر بها العرب عن أغراضهم. وقد وصلت إلينا من فئن طريق النقل. وحفظها لنا القرآن الكريع والأحاديث الشريفة. وما رواه الثقات من منشور العرب ومنظومهم"3. وهي أيضا لغة القرآن الكريمُ .وارتبطت اللغة العربية بالإسلام ارتباطا كبيرا، لأها اللغة الدينية لجميع المسلمين في جميع أنحاء العالم سواء كانوا يتكلمون العربية أو لا يتكلموها فهم، أي المسلمون، يتلون القرآن في أصله العربي، وليست هناك ترجمة في أية لغة بككن أن نستخدم بديلا عن الأصل العربك. ولا شك أن الفهم به

1 عبد الحليم حنفي،طرق تعليم اللغة العربية، (باتوسنكر: جامعة باتوسنكر الإسلامية الحكومية، 2005)

2جودات الركابي،طرق تدريس اللغة العربية, (دمشق: دار الفكر، 1996)، ص. 5.

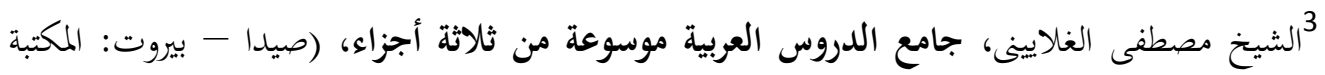
العصرية، 1423 هـ - 2003 م)، ص 9.

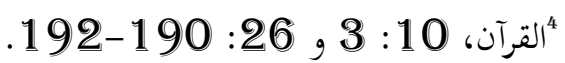

55تحى عليى يونس ومحمد عبد الرؤوف الشيخ، المرجع في تعليم اللغة العربية للأجانب (من النظرية إلى 1920 الى

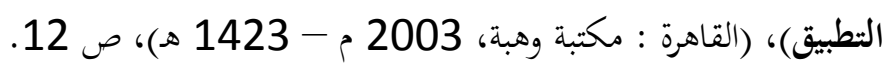


شيئ ضروري لأنه مصدر أول لتعاليم الإسلام كما أن دراسة اللغة العربية شيئ هام

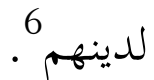

لذلك، اللغة العربية آلة من الآلات المهمة للاتصال إلى فهم دين الإسلام من مصادره الأصلية، وهما القرآن الكريع والأحاديث الشريفة. وهي ما تدفع المسلمين لتعليم اللغة العربية وتعلّمها. أما أهداف تعليم اللغة العربية فهي: - مي 1 - ا فهم ما يقرأه الناس في الصلاة. 2- فهم قراءة القرآن، حتى يستطيع الناس أن يأحذوا العبرة منه. 3- أن يستطيع الإنسان تعلم علوم الدين في الكتب العربية ، كعلوم القرآن والحديث

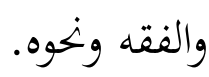
4- وأن يستطيع كتابة النص باللغة العربية في المعاملة مع المسلمين خارج البلاد. لأن اللغة العربية لغة المسلمين، بل الآن، تكون اللغة العالمية. لذلك، ليس تعليم اللغة العربية لفهم اللغة فحسب، بل هو لقدرة فهم النص باللغة العربية أيضا. إذن، لابد من الناس لقدرة الترجمة باللغة الجيدة. وإن الترجمة "نقل معنى

$$
\text { 6أمد الهاشمي، القواعد الأساسية اللغة العربية، (بيروت: مكتبة لبان، د.ت.)، ص } 3 .
$$




$$
\begin{aligned}
& \text { النص من لغة إلى أخرى"7" وهي "نقل المعنى من لغة المصدر إلى لغة المدف"8 } \\
& \text { إحدى تعاليم اللغة العربية. للمترجم الطيب شروط، كما يأتي : } \\
& \text { 1 - فهم القواعد والترجمة } \\
& \text { 2 - 2 - لديه مفردات كثيرة } \\
& \text { 3- لديه علوم اجتماعية وفكر واسع · }
\end{aligned}
$$$$
\text { واللغة العربية تتكون من العناصر، هي الأصوات والمفردات والتراكيب والبلاغة وغير }
$$$$
\text { ذلك، والمفردات إحدى العوامل الهامة في اللغة. كلما فهم التلاميذ على مفردات كثيرة }
$$$$
\text { فسهلوا الاتصال وظهورة الفكر باستعمال اللغة، وعكسها إن كان استيعاب المفردات }
$$$$
\text { ضعيفا فصعبت عليهم اتصال جيدا، وكذلك على الترجة. المفردات إحدى العناصر }
$$$$
\text { المهمة في اللغة، لأكها تنفع على مشكل النطق والكلمة والنص. لذلك، لابد للتلاميذ أن }
$$$$
\text { يبدؤوا بمعرفة المفردات وتعلمها في تعليم اللغة الأجنبية، لو كانت بحفظها أم غيرها } 10 .
$$

7أسعد مظفّر الدّين حكيم، علم الترجمة النظري، (دمشق: طلاسدار، 1988). ص. 38.

8 A. Widyamartaya, SeniMenerjemah, (Yogyakarta: Kanisius, 1989), h. 11.

9 Tayar Yusuf danSyaiful Anwar, MetodologiPengajaran Agama danBahasa Arab, (Jakarta: PT. RajaGrafindoPersada, 1997), h. 170.

${ }^{10}$ Muhbib Abdul Wahab, Epistimologi\&MetodologiPembelajaranBahaasa Arab, (Jakarta:LembagaPenelitian UIN SyarifHidayatullahJakarta, 2008), h. 149. 
بعد ما لاحظت الكاتبة في المدرسة الثانوية الحكومية باتوسنكر، فكانت المدرسة إحدى المدارس الدينية في اندونيسيا، ومادة من مواد التعليم فيها اللغة العربية التي تتكون من المهارات الأربع، هي مهارة الاستماع والكلام والقراءة والكتابة، ولكل المهارة أهداف مختلفة. أما مهارة القراءة فلابد على التلاميذ ليترجموا نص القراءة لفهمها، لأن فهم نص القراءة هدف من أهداف مهارة القراءة،وتستخدم المدرسة مفردات مناسبة بالطرق والوسائل المختلفة قبلها.

ثم قامت الكاتبة بالمقابلة مع مدرسة اللغة العربية، قالت المدرّسة أها تستخدم المفردات على التلاميذ قبل أن يترجموا نص القراءة من تعليم اللغة العربية لعلهم يستطيعون أن يترجموا سهلا، ولكن قدرة التلاميذ على ترجمة نص القراءة غير جيد في هذه المدرسة، منهم لا يستطيعون في الترجمة، بل كانوا قليلا من التلاميذ الذين يستطيعون في الترجمة بالجيد11.

إذا نظرت الكاتبة إلى وظيفة استيعاب المفردات فهي إحدى عوامل اللغة العربية وهي التي تحتاج إليها في الترجمة، لأفا عاملة من عوامل الترجمة الجيدة. إذا كان لدى التلاميذ مفردات كثيرة فقدرقم على ترجمة نص القراءة من تعليم اللغة العربية جيدة، وبالعكس.

11, ${ }^{11}$ مقابلة، المدرسة الثانوية الحكومية بباتوسنكر، يوم الثلاثاء في التاريخ 19 اكتوبر 2010. Jurnal WARAQAT $\bullet$ Volume I, No. 1, Januari-Juni 2016 | 5 
لإجابة هذه المشكلة، تستعمل الكاتبة منهجية البحث الكمي بالنوع العلاقي، وتستعمل طريقة إحصائية لأن الكاتبة تبحث عن العلاقة بين استيعاب المفردات لدى التلاميذ وقدرقم على ترجمة نص القراءة من تعليم اللغة العربية. وتبحث الكاتبة في المدرسة الثانوية الحكومية بباتوسنكر في السنة 2011.

أما بجتمع البحث لهذه الرسالة فهو تلاميذ المدرسة الثانوية الحكومية بباتوسنكر في الفصل السابع من خمس فصول، وعددهم 165 تلميذا. وتأخذ الكاتبة العينة بطريقة Kluster Sampling وتأخذها تلاميذ في الفصل السابع - 3 بعددهم 28تلميذا. وأداة البحث لجمعات البيانات المستعملة في البحث امتحان، بمعنى إقامة الكاتبة بالامتحان على التلاميذ لمعرفة استيعاهم على المفردات، ثم إقامة الكاتبة امتحان على التلاميذ لمعرفة قدرقم على ترجمة نص القراءة من تعليم اللغة العربية. كان الامتحان كتابيا، فتنظر الكاتبة إلى الدرجة بينهما. بعدما وجدت الكاتبة البيانات عما يتعلق بالبحث، فجمعها في الجدول ثم صنفها باستعمال الرمز Moment Product Korelasi وحللتها الكاتبة تحليلا كميا إحصائيا وجعلتها أساسية في استنباط الخلاصة من بحث هذه الرسالة.

\footnotetext{
${ }^{12}$ Anas Sudijono, PengantarStatistikPendidikan, (Jakarta: GrafindoPersada, 2005), h. 206.
} 


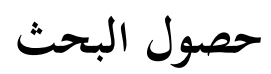

جمعت الكاتبة البيانات لمعرفة استيعاب المفردات لدى التلاميذ (متغيرةX) بإعطاء

الامتحان إلى عينة البحث. وكذلك أيضا بالبيانات لمعرفة قدرة التلاميذ على ترجمة نص

القراءة من تعليم اللغة العربية (متغيرةY). ووجدت الكاتبة من الامتحان كما في الجدول

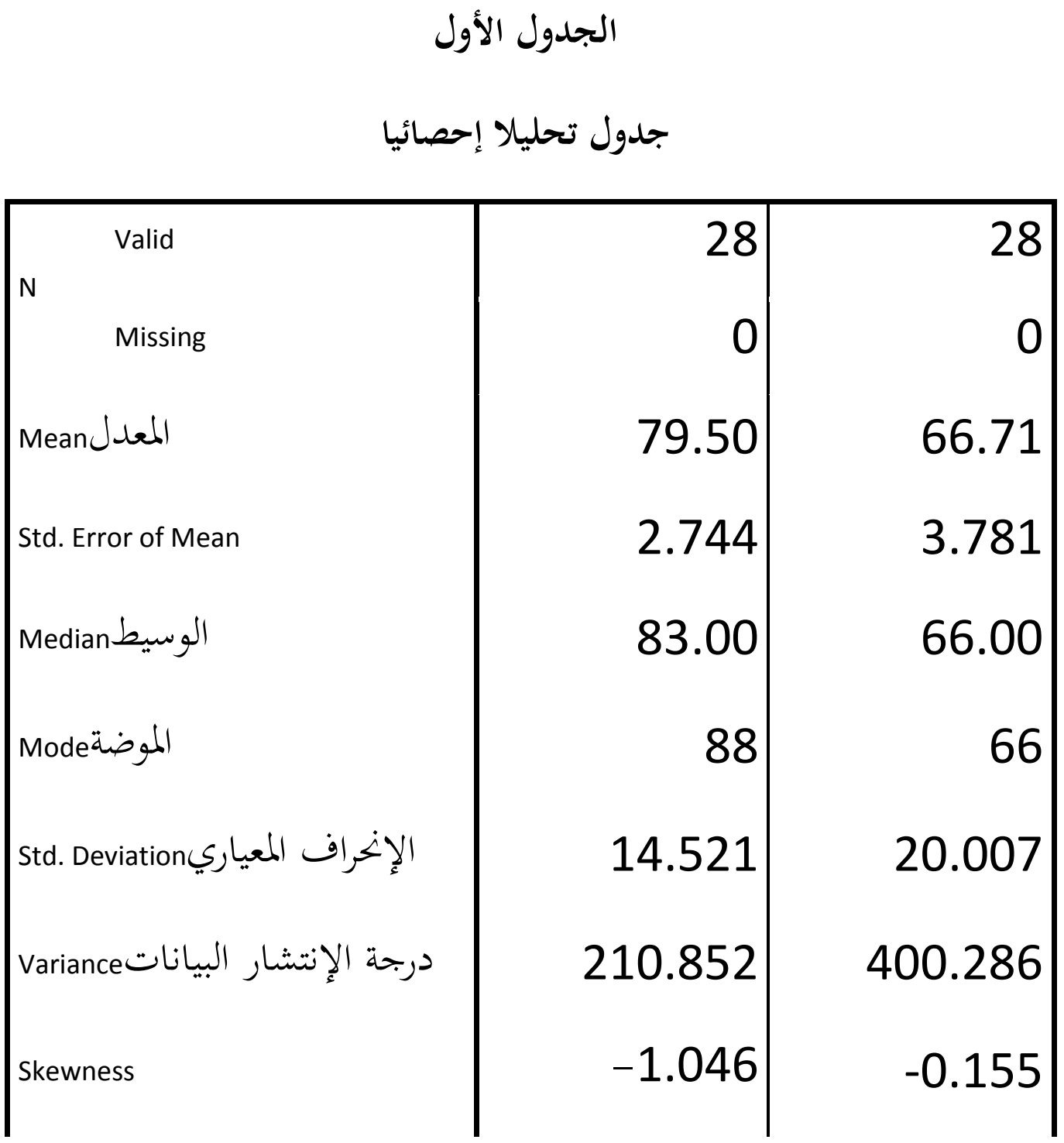




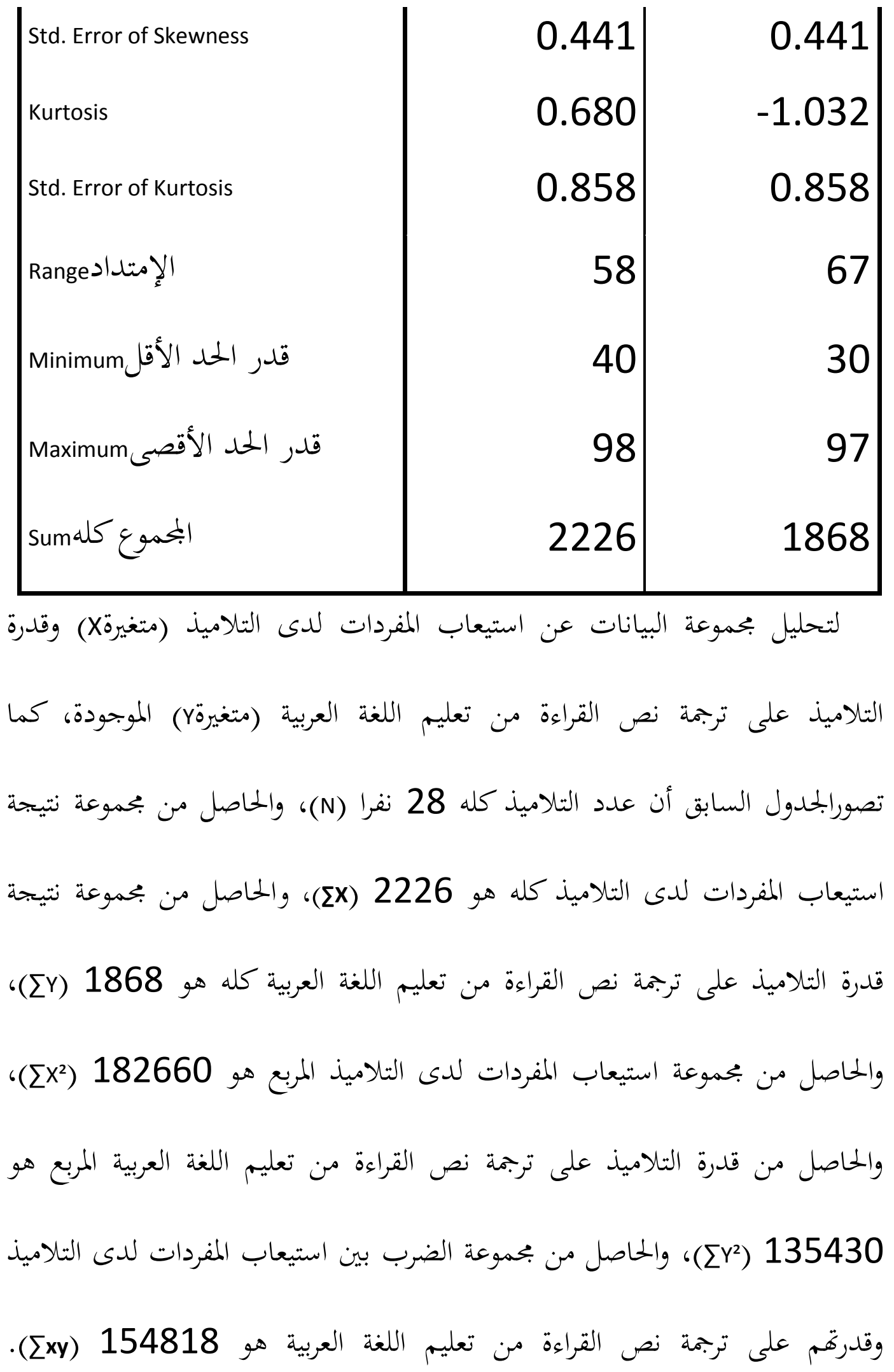


فاستعملت الكاتبة الرمزKorelasiProductMoment، لتحليل البيانات بأن تستعمل الكاتبة حاسوب Program SPSS versi18، توجد الحصل كما في الجدول الآتي :

$$
\text { الجدول الثاني }
$$

جدول حاصل العلاقة بين استيعاب المفرداتلدى التلاميذ

وقدرتهم على ترجمة نص القراءة من تعليم اللغة العربية

\section{Correlations}

\begin{tabular}{|c|c|c|c|}
\hline & & $\bar{Y}$ & $\bar{X}$ \\
\hline Y & $\begin{array}{l}\text { Pearson Correlation } \\
\text { Sig. (2-tailed) } \\
\mathrm{N}\end{array}$ & \begin{tabular}{r|}
1 \\
28
\end{tabular} & $\begin{array}{r}0.805^{* *} \\
0.000 \\
28\end{array}$ \\
\hline$X$ & $\begin{array}{l}\text { Pearson Correlation } \\
\text { Sig. (2-tailed) } \\
\mathrm{N}\end{array}$ & $\begin{array}{r}0.805^{* *} \\
0.000 \\
28\end{array}$ & 28 \\
\hline
\end{tabular}

**. Correlation is significant at the 0.01 level (2-tailed).

صور البيان السابق حاصل العلاقة بين استيعاب المفردات لدى التلاميذ وقدرقم على ترجمة نص القراءة من تعليم اللغة العربية بـ "rxy" هو 0.805.

المعروف أن نتيجة العلاقة بين متغيرة x (استيعاب المفرداتلدى التلاميذ) ومتغيرة (قدرة التلاميذ على ترجمة نص القراءة من تعليم اللغة العربية) هي 0.805. أما لمعرفة العلاقة بينهما، فتفسر الكاتبة هذه النتيجة باستعمال الطريقتين، وهما: 


$$
\text { 1 - - بريقة حساب العلاقة }
$$

بناء على الحاصل السابق حاصل العلاقة بينهما 0،805 فتفسير لهذا الحاصل هي هناك العلاقة بين متغيرة ومتغيرة y. كما قال في كتاب الذي كتبه عبد الحليم حنفي عن تفسير نتائج العلاقة بين متغيرتين (متغيرة X و متغيرة Y) فهو ما يلي:

الجدول الثالثة

جدول تفسير النتائج

\begin{tabular}{|c|c|}
\hline "r" & تفسير النتائج \\
\hline 0،00 إلى 0،20 & دون العلاقة \\
\hline 0،21 إلى 40، & العلاقة المنخفضة \\
\hline 0،40، 0.60 إلى & العلاقة المتوسطة \\
\hline 0،61 إلى 80، & العلاقة المرتفعة \\
\hline 810، إلى 001،13 & العلاقة الكاملة \\
\hline
\end{tabular}

بناء على الحاصل السابق أن نتيجةrxy فهي 0،805، وهي تقع في $61 ، 0$

Y ومتغيرة X0،0 بناء على جدول السابق فعرفها أن العلاقة بين متغيرة

${ }^{13}$ Abdul HalimHanafi,MetodologiPenelitianBahasa,(Batusangkar: STAIN Batusangkar Press, 2007) h. 91. 
علاقة مرتفعة. لذلك، تستنبطه الكاتبة أن توجد علاقة مرتفعة بين متغيرة X ومتغيرة

$$
\text { بطريقة حساب العلاقة. }
$$$$
\text { 2- - طريقة العلاقة باستعمال جدول نتائجr }
$$

أما تفسير النتيجة باستعمال جدول نتائج r، فهو بعض الخطوات التي لابد

$$
\text { للكاتبة أن تستعملها هي : }
$$

تعبير الفروض العلمية التبادلية(Alternatif (Ha): كانت العلاقة الإيجابية المدلولة

بين متغيرة X(استيعاب المفرداتلدى التلاميذ) ومتغيرة(قدرة التلاميذ على

$$
\text { ترجمة نص القراءة من تعليم اللغة العربية). }
$$

ب) تعبير الفروض العلمية العدمية(Nol / Nihil (Ho) لم تكن العلاقة الإيجابية المدلولة بين متغيرةX(استيعاب المفرداتلدى التلاميذ) ومتغيرةY(قدرة التلاميذ

$$
\text { على ترجمة نص القراءة من تعليم اللغة العربية). }
$$

في هذا البحث تريد الكاتبة لإنتشارة بقيمة rxy

في الدرجة 5\% و 1\%. أما الخطوة الأولى التي تستعملها الكاتبة فهي تبحث عن

$$
\text { قيمة أو نتيجة درجة حرورية (db) بالرمز: }
$$

$$
\mathrm{db}=\mathrm{N}-\mathrm{nr}
$$




$$
\begin{aligned}
\text { الإيضاح : } & \text { db درجة حرورية }=\mathrm{N} \\
\text { متحموعة }=\mathrm{nr} &
\end{aligned}
$$

إذا كان N مجموعة في هذا البحث هي 28 تلميذا و 2 =nr 2 فكانت

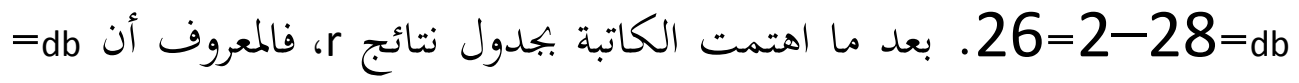

$$
26 \text { في الدرجة } 5 \text { \% نتيجتها } 37460 \text { وفي الدرجة 1\% نتيجتها 0.478. }
$$

وإذا كان ro أكبر من rt فالفروض العلمية التبادلية Alternatif (Ha) مقبولة

والفروض العدمية Nol / Nihil (Ho) مردودة وبالعكس إذا كان ro أقل من rt فالفروض

Nol / Nihil Alternatif (Ha) مردودة والفروض العلمية العدمية التبادلية

مقبولة.(Ho)

وفي هذا البحث كانت نتيجة ro أكبر من rt وهي

فالفروض العدمية Nol / Nihil (Ho) مردودة و الفروض العلمية التبادلية(Hatternatif (Ha) مقبولة. إذن، في الدرجة 5\% توجد علاقة إيجابية مثقة بين متغيرةXومتغيرةY.والتالي في الدرجة 1\% نتيجة rt أصغر من ro وهي 0,478، إذن في الدرجة 1\% فالفروض العدمية Nol / Nihil (Ho) مردودة والفروض العلمية التبادلية Ha) Alternatif 
مقبولة أيضا، بمعنى في درجة 1\% توجد علاقة إيجابية مثقة بين متغيرة X ومتغيرة

وإذا تري الكاتبة من طريقة إبتحاه العلاقة ففيها يدل على (-) سلبية و(+)

إيجابية. العلاقة تدل على (-) سلبية هي إذا كانت X مرتفعة، ف Yضعيفة وتدل على (+) إيجابية هي إذا كانت X مرتفعة ف Y مرتفعة أيضا. ومن البحث كانت 0.805، وهي تدل على (+) إيجابية، يعني إذا كان X مرتفع ف Y مرتفع أيضا. إذن، إذا كان استيعاب المفردات لدى التلاميذ مرتفع فقدرقم على ترجمة نص القراءة من تعليم اللغة العربية مرتفعة أيضا.

والخلاصة من البيان السابق أن استيعاب المفردات وقدرة ترجمة نص القراءة من تعليم اللغة العربية يتأثران، وكانت العلاقة بينهما علاقة مرتفعة، والعلاقة مقبولة أو العلاقة الإيجابية تدل على (+) إيجابية، إن كان استيعاب المفردات لدى التلاميذ مرتفعا فقدرتم على ترجمة نص القراءة من تعليم اللغة العربية مرتفعة أيضا. المعروف أن قدرة الترجمة تؤثر على العوامل الكثيرة، كما قال تاير يوسف وسيف الأنوار أن للمترجم الطيب شروط، كما يأتي : 1 - - مهم القواعد والترجمة 


$$
\text { 2 - 2 - لديه مفردات كثيرة }
$$

$$
\text { 3- - لديه علوم اجتماعية وفكر واسع } 14
$$

من العوامل السابقة اتضحتها الكاتبة أن استيعاب المفردات هو عامل من العوامل التي تؤثر في قدرة الترجمة. ولا شك أن ترجمة نص القراءة من تعليم اللغة الأجنبية، كاللغة الإبجيلزية ونهوها تحتاج إلى استيعاب المفردات لأن كثيرا من المفردات من أهم العوامل في الترجمة.

حاصل البحث عن العلاقة بين استيعاب المفردات لدى التلاميذ وقدرةم على ترجمة نص القراءة من اللغة العربية تصور أن استيعاب المفردات لدى التلاميذ لقدرقم على ترجمة نص القراءة من تعليم اللغة العربية هما علاقيا إيجابيا ومرتفعا. بناء على البحث السابق أن استيعاب المفردات لدى التلاميذ علاقية بقدرقم على ترجمة نص القراءة من تعليم اللغة العربية في المدرسة الثانوية الحكومية باتوسنكر. هذه العلاقة مرتفعة وهي إيجابية، وإذا تنظر إلى الآراء من علماء السابقة أن بين استيعاب المفردات وقدرة على الترجمة علاقة مرتفعة.

\footnotetext{
${ }^{14}$ Tayar Yusuf dan.Syaiful Anwar, op.cit., h. 170.
} 


\section{خلاصة}

بناء على البحث السابق أن استيعاب المفردات لدى التلاميذ علاقة بقدرةم على ترجمة نص القراءة من تعليم اللغة العربية في المدرسة الثانوية الحكومية باتوسنكر. فيها بالعلاقة 805،0، وبالعروض العدمية مردودة والعروض التبادلية مقبولة في الدرجة 5\% هي 374،0 وفي الدرجة 1\% هي 478،0. والعلاقة مرتفعة و إيجابية، وإذا تنظر الكاتبة إلى الآراء من علماء السابقة أنه بين استيعاب المفردات وقدرة على الترجمة علاقة

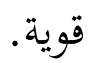
إذن، بناء على ذلك فالخلاصة أن توجد العلاقة الإيجابية بين استيعاب المفردات لدى التلاميذ وقدرقم على ترجمة نص القراءة من تعليم اللغة العربية في المدرسة الثانوية الحكومية باتوسنكر. وكانت علاقة بينهما علاقة مرتفعة وإيجابية، وهي إذا كان استيعاب المفردات لدى التلاميذ مرتفعة فقدرقم على ترجمة نص القراءة من تعليم اللغة العربية مرتفعة أيضا. قائمة المراجع القرآن الكريم 


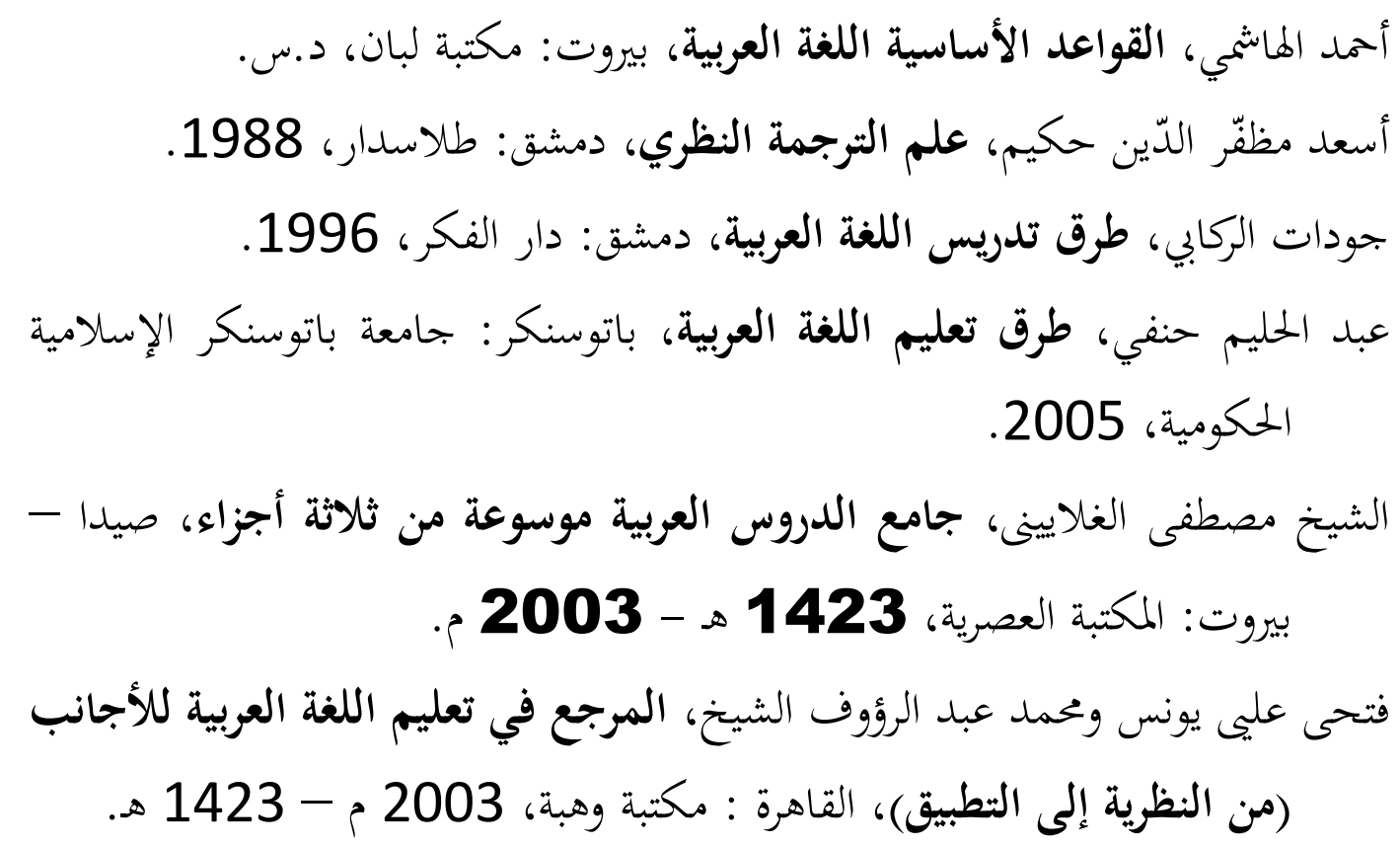

Widyamartaya, A., Seni Menerjemah, Yogyakarta: Kanisius, 1989.

Yusuf, Tayardan Syaiful Anwar, Metodologi Pengajaran Agama dan Bahasa Arab, Jakarta: PT. Raja Grafindo Persada, 1997.

Wahab, Muhbib Abdul, Epistimologi\&Metodologi Pembelajaran Bahaasa Arab, Jakarta: Lembaga Penelitian UIN Syarif Hidayatullah Jakarta, 2008.

Sudijono, Anas, Pengantar Statistik Pendidikan, Jakarta: GrafindoPersada, 2005.

Hanafi, Abdul Halim, Metodologi Penelitian Bahasa, Batusangkar: STAIN Batusangkar Press, 2007. 
